\title{
HACking the centromere chromatin code: insights from human artificial chromosomes
}

\author{
Jan H. Bergmann • Nuno M. C. Martins • \\ Vladimir Larionov • Hiroshi Masumoto • \\ William C. Earnshaw
}

Published online: 24 July 2012

(C) Springer Science+Business Media B.V. 2012

\begin{abstract}
The centromere is a specialized chromosomal region that serves as the assembly site of the kinetochore. At the centromere, CENP-A nucleosomes form part of a chromatin landscape termed centrochromatin. This chromatin environment conveys epigenetic marks regulating kinetochore formation. Recent work sheds light on the intricate relationship between centrochromatin state, the CENP-A assembly pathway and the maintenance of centromere function. Here, we review the emerging picture of how chromatin affects mammalian kinetochore formation. We place particular emphasis on data obtained from Human Artificial Chromosome (HAC) biology and the targeted engineering of centrochromatin using synthetic HACs. We discuss implications of these findings, which indicate that a delicate balance of histone
\end{abstract}

Responsible Editor: Rachel O'Neill and Beth Sullivan.

\section{J. H. Bergmann}

Cold Spring Harbor Laboratory,

One Bungtown Road,

Cold Spring Harbor, NY 11724, USA

J. H. Bergmann

e-mail: jbergmann@cshl.edu

N. M. C. Martins • W. C. Earnshaw $(\bowtie)$

Wellcome Trust Centre for Cell Biology,

University of Edinburgh,

King's Buildings, Mayfield Road,

Edinburgh EH9 3JR, Scotland, UK

e-mail: bill.earnshaw@ed.ac.uk

N. M. C. Martins

e-mail: N.N.Martins@sms.ed.ac.uk modifications and chromatin state dictates both de novo centromere formation and the maintenance of centromere identity in dividing cell populations.

Keywords centromere - kinetochore C CENP-A . epigenetics $\cdot$ chromatin $\cdot$ human artificial chromosome
Abbreviations
CCAN Constitutive centromere-associated network
FACT Facilitates in chromatin transcription
HAC Human artificial chromosome
HAT Histone acetyl-transferase
HJURP Holiday junction recognition protein
HP1 Heterochromatin protein 1
tetO Tetracycline operator
tetR Tetracycline repressor 
TSA Trichostatin A

YAC Yeast artificial chromosome

\section{Introduction}

The centromere is a specialized chromosomal region that defines the site of assembly of the kinetochorethe complex super-structure that regulates chromosome segregation in mitosis. In humans, centromeres typically consist of a complex repetitive $\alpha$-satellite DNA array comprised of tandemly arranged A/T-rich 171 bp monomer units (Choo et al. 1991). These repetitive DNA loci span hundreds of kilobases to megabases (Willard 1985; Willard 1990). Centromeric $\alpha$-satellite DNA arrays are of two types. The centromeric "core" associated with the kinetochore typically consists of regular repeating hierarchical families of repeats with a monomer consensus of $171 \mathrm{bp}$, and containing one or more 17 bp "CENP-B boxes" per higher-order repeat (Masumoto et al. 1989). The latter are binding sites for the protein CENP-B (Earnshaw and Rothfield 1985; Earnshaw et al. 1987). In some centromeres, this core of alphoid type I DNA is flanked by type II alphoid DNA, which lacks a higher-order repeat organisation and also lacks CENP-B boxes (Ikeno et al. 1994; Schueler et al. 2001).

In extremely rare instances where the centromere has been lost - typically due to chromosome breakagecentromeres can form on non-centromeric DNA. These neocentromeres (Voullaire et al. 1993; du Sart et al. 1997; Warburton et al. 1997; Saffery et al. 2000; Lo et al. 2001; Warburton 2001; Alonso et al. 2003; Alonso et al. 2007) lack $\alpha$-satellite DNA, and therefore lack CENP-B, but appear in all other respects to be structurally normal, functional and heritable. Thus, there is no absolute requirement for any particular DNA sequence to define a genetically stable centromere. It therefore appears that centromeric loci are defined by an epigenetic mark that is not specified by the primary DNA sequence. The first evidence for this was the characterisation of stable dicentric chromosomes, containing two spatially distinct $\alpha$-satellite domains, only one of which nucleates active kinetochore assembly (Merry et al. 1985; Earnshaw and Migeon 1985). Since the inactive $\alpha$-satellite locus contains thousands of copies of the underlying DNA sequence, it is exceedingly unlikely that it could be inactivated as a result of specific mutations of the underlying DNA. This led to the suggestion that centromere assembly is regulated by the chromatin status (Earnshaw and Migeon 1985), or as it was subsequently termed - by epigenetic factors (Sullivan and Schwartz 1995; Karpen and Allshire 1997; Vafa and Sullivan 1997, Warburton et al. 1997; Sugata et al. 2000).

A key to what this specialized chromatin might be came with the realisation that CENP-A, one of the first kinetochore proteins to be identified (Earnshaw and Rothfield 1985) is a specialized histone $\mathrm{H} 3$ variant that distinguishes the centromere as a unique chromatin domain from any other region of the chromosome (Palmer and Margolis 1987; Palmer et al. 1991; Sullivan et al. 1994). In essentially all species, CENP-A localizes exclusively to active centromeres, including those of human artificial chromosomes (HACs) (Ohzeki et al. 2002; Okamoto et al. 2007), dicentric chromosomes and neocentromeres (Earnshaw et al. 1989; Warburton et al. 1997; Lo et al. 2001; Alonso et al. 2007).

CENP-A stands at the apex of a complex protein hierarchy that specifies the transient formation of the functioning mitotic kinetochore. Downstream of CENP$\mathrm{A}$ is the constitutive centromere-associated network (CCAN), formed by 16 proteins present at centromeres throughout the cell cycle (Cheeseman and Desai 2008). The proper localisation of almost all CCAN members is critically dependent on CENP-A (Oegema et al. 2001; Goshima et al. 2003; Liu et al. 2006; Hori et al. 2008; Carroll et al. 2009), prompting the proposal that CENP-A could act as an epigenetic mark responsible for the maintenance of centromere identity (Karpen and Allshire 1997; Vafa and Sullivan 1997; Warburton et al. 1997; Sugata et al. 2000; Cleveland et al. 2003; Allshire and Karpen 2008; Black and Bassett 2008). Indeed, forced over-expression of CENP-A results in its localisation to chromosome arms and can in Drosophila result in the formation of an ectopic kinetochore (Heun et al. 2006; Mendiburo et al. 2012). In other circumstances, CENP-A overexpression is not sufficient to nucleate kinetochore formation (Van Hooser et al. 2001), and it appears that other aspects of the chromatin environment must be involved.

Microscopic investigation of stretched kinetochore fibers revealed that blocks of CENP-A nucleosomes are interspersed with nucleosomes containing canonical histone H3 as well as CENP-T/W/S/X "nucleosomes" (Nishino et al. 2012). This pattern is found at endogenous centromeres of several higher eukaryotes (Blower et al. 2002; Ribeiro et al. 2010) and at functional neocentromeres (Chueh et al. 2005; Alonso et al. 


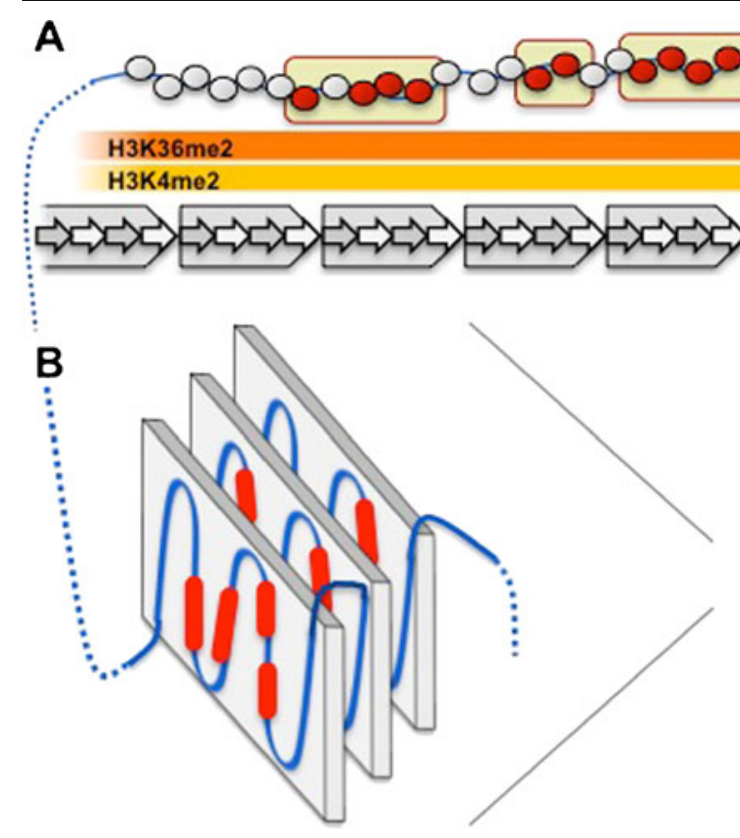

Fig. 1 CENP-A is embedded in a specialized chromatin compartment. a Linear depiction of human centromeric $\alpha$-satellite DNA. Blocks of red CENP-A nucleosomes (yellow shaded boxes) are interspersed with grey nucleosomes containing canonical histone H3. CENP-A associates with type I $\alpha$-satellite repeats that are arranged in a tandem higher-order array. Type II repeats associated with pericentric heterochromatin lack this

2007). In humans, Drosophila and chicken DT40 cells, these interspersed nucleosomes are hypoacetylated and display variable levels of histone $\mathrm{H} 3$ lysine 4 di-methylation (H3K4me2) and H3K36diand tri-methylation in the absence of detectable H3K4me3 (Sullivan and Karpen 2004; Ribeiro et al. 2010, Bergmann et al. 2011). Overall, the unique nucleosomal composition at centromeres has been termed "centrochromatin" (Sullivan and Karpen 2004) (Fig. 1). The contribution of centrochromatin to the regulation of CENP-A deposition and replication has been a topic of intense speculation, as this offers an obvious key to the epigenetic maintenance of centromere identity (Sullivan and Karpen 2004; Allshire and Karpen 2008; Ribeiro et al. 2010). A role of chromatin modifications in regulating other processes such as transcription, DNA replication, DNA repair and telomere maintenance is well documented (Berger 2007; Blasco 2007; Dinant et al. 2008; Alabert and Groth 2012).

The above observations raise several questions about the exact nature of the chromatin that specifies kinetochore assembly and propagation. For centromeres, aside from CENP-A, what combination of
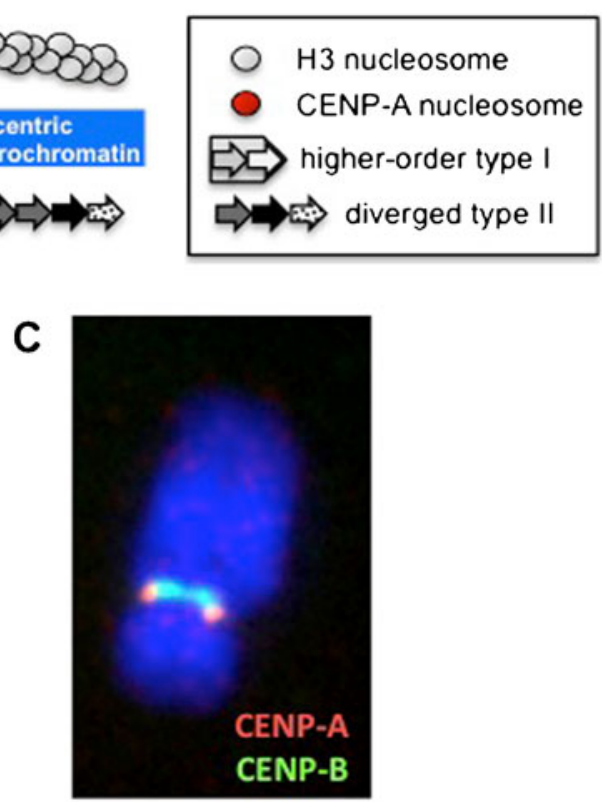

higher order structure. b CENP-A domains are proposed to be embedded in an anti-parallel, multi-layered higher-order chromatin "boustrophedon" arrangement (Ribeiro et al. 2010). On the mitotic chromosome (c), this arrangement causes CENP-A to aggregate on the chromosome surface. Micrograph by Peter Warburton and WCE (Warburton et al. 1997)

histone modifications defines the elusive epigenetic state that is centrochromatin? Do these vary as a function of cell cycle phase? And can they be manipulated to turn normal chromatin into centrochromatin and the reverse - to inactivate established centromeres?

\section{Human artificial chromosomes as models for de novo kinetochore formation and function}

Answering these questions with native human chromosomes is extremely challenging. Aside from the fact that the sequence of centromeric DNA arrays remains largely uncharted territory, even in these days of the 1,000 Genomes project, the use of RNAi or inhibitors to manipulate the composition of centrochromatin is fraught with difficulties beyond the usual specificity issues associated with both of those approaches. In particular, even if methods for interfering with chosen chromatinmodifying enzymes were wholly specific, the fact that these enzymes likely act on a plethora of non-chromatin substrates despite their convenient names- "histone acetyltransferases", "histone deacetylases" makes the 
interpretation of such experiments nearly impossible (Huang and Berger 2008; Spange et al. 2009). A new approach is therefore needed, and recent work suggests that, as was the case in indentifying the key determinants of chromosome segregation in yeasts (Stinchcomb et al. 1979; Clarke and Carbon 1980; Szostak and Blackburn 1982; Murray and Szostak 1983), the development of artificial chromosomes may provide a key step forward.

\section{From shotgun cloning to designer higher-order arrays: a brief history of HACs}

In addition to providing valuable vectors for the cloning of large DNA sequences and their promises for gene delivery and therapy (Burke et al. 1987; Basu and Willard 2005; Tsuduki et al. 2006; Yamada et al. 2008), both of which are not dealt with in this review, human artificial chromosomes (HACs) mimic endogenous chromosomes in kinetochore structure and mitotic behaviour (Nakashima et al. 2005) and are amenable to controlled manipulation without affecting endogenous chromosomes and overall cell viability.

The first mitotically stable human artificial chromosomes (HACs) were obtained by co-transfection of cloned human $\alpha$-satellite DNA and telomeric sequences together with random genomic DNA into HT1080 fibrosarcoma cells (Harrington et al. 1997). The utility of this approach for studying centromere structure and function was limited, due the inherent uncertainty of the composition of the resulting HACs. Ikeno et al. (1998) employed a more defined approach by applying YAC (yeast artificial chromosome) construction methods to HAC building: $100 \mathrm{~kb}$ of human type I $\alpha$-satellite DNA from chromosome $21(\alpha-21-\mathrm{I})$ was cloned into a YAC vector and retro-fitted with human telomere sequences. When this linear construct was introduced into HT1080 cells, about $30 \%$ of the resulting clones carried HACs, with the remaining cells displaying integration of the input DNA into endogenous chromosomes. HACs ranged in size between 1 and $5 \mathrm{Mbp}$, indicating that multimerization of the input DNA had occurred, although detectable host sequences remained absent. Multimerization of the input DNA is a common feature of de novo HAC formation by various methods and may represent an obligate step in HAC formation.

Ebersole et al. (2000) subsequently pioneered the generation of HACs from defined, circular input
DNA lacking telomeric repeats. A minimal phage P1 artificial chromosome vector carrying $70 \mathrm{~kb}$ of $\alpha$-21-I $\alpha$-satellite DNA surprisingly yielded HACcarrying transformants at a frequency comparable to that observed using linear, telomere-fitted input DNA. In situ hybridization revealed multimerization of the circular input DNA and confirmed that the resulting HACs had not acquired host telomeric DNA, suggesting their episomal maintenance as mitotically highly stable, circular chromosomes.

This approach using defined, circular input DNA for HAC formation offers the valuable advantage that the sequence of the input DNA can be readily manipulated in bacteria and yeast before it is introduced into human cells. Combined with the exploitation of phage rolling circle amplification (RCA) and yeast transformationassociated recombination (TAR) cloning to generate thousands of kilobases of tandem repeats (Ebersole et al. 2005), this RCA-TAR approach formed the basis for the generation of entirely synthetic alphoid arrays and their study in de novo centromere formation or kinetochore maintenance, as discussed in the subsequent sections.

The synthetic "alphoid ${ }^{\text {tetO }}$ array" assembled by RCATAR has occupied centre stage in a range of these studies (Nakano et al. 2008) (Fig. 2). The base repeat unit of the alphoid $^{\text {tetO }}$ array is a dimer, originally comprising one chromosome $17 \alpha$-satellite monomer with CENP-B box (Waye and Willard 1986), and a second $\alpha$-satellite consensus monomer (Choo et al. 1991) containing the 47 bp Escherichia coli tetO (tetracycline operator) in place of the CENP-B box. TetO sites are recognized by the tetR (tetracycline repressor) protein in a doxycyclinecontrollable manner, thus allowing the specific and conditional tethering of tetR fusion proteins to the alphoid ${ }^{\text {tetO }}$ array (Fig. 2). More recent synthetic alphoid ${ }^{\text {tetO }}$ constructs have utilized a native dimer from chromosome $21 \alpha$-21-I DNA, in which a tetO has been inserted into the monomer lacking the CENP-B box (Ohzeki et al. 2012).

\section{CENP-B: deciding the fate of $\alpha$-satellites}

Early HAC formation studies shed light on the requirements for the establishment of de novo centromere function on transfected $\alpha$-satellite DNA. One critical factor proved to be the type of $\alpha$-satellite DNA, which must be a regular repeating array containing at least one monomer with a CENP-B box (Ikeno et al. 1998). Type I satellites derived from the Y chromosome, which does 


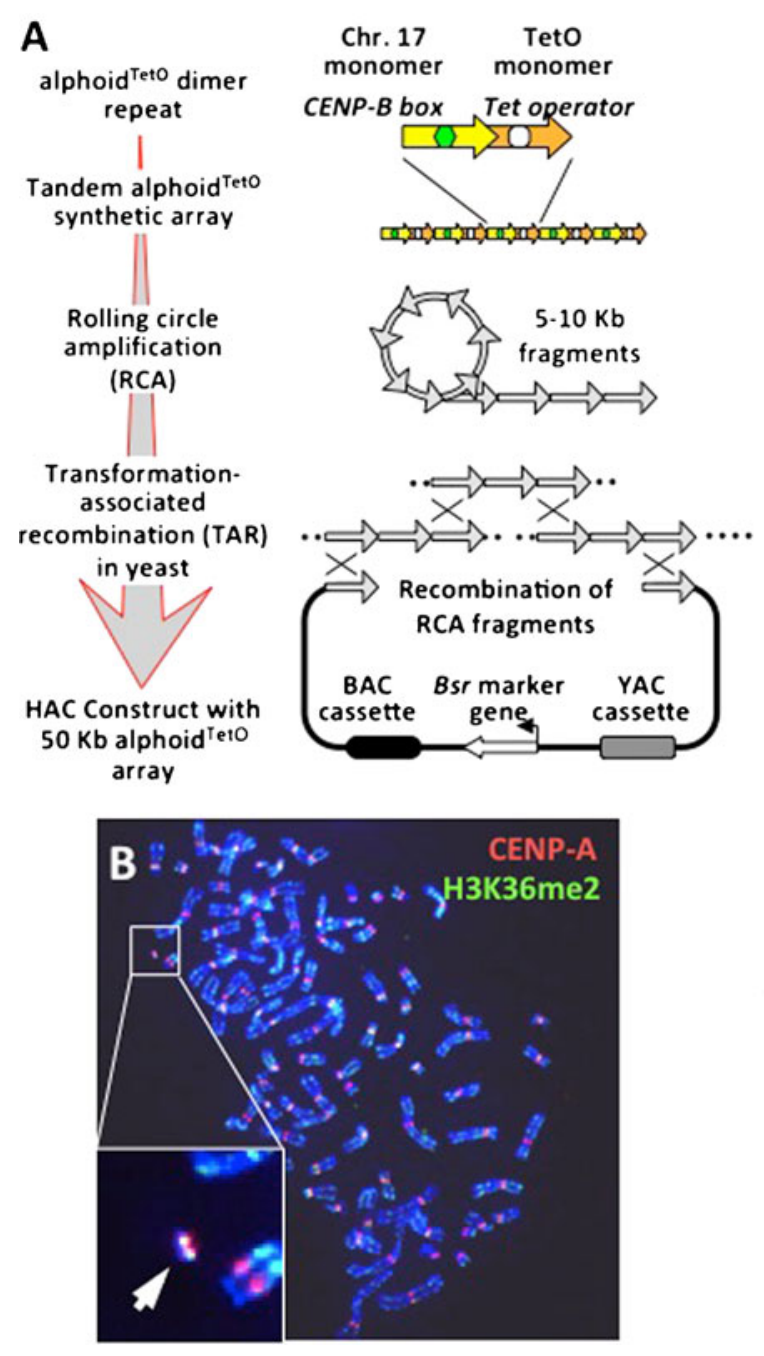

A

Fig. 2 Assembly of the alphoid ${ }^{\text {tetO }}$ array and HAC. a HAC construction strategy: an $\alpha$ satellite dimer, consisting of a monomer from chromosome 17 and a synthetic monomer with a Tet operator (TetO) sequence in place of a CENP-B box, was cloned head-to-tail to generate an 8-mer that was subsequently subjected to rolling circle amplification. The resulting amplification products were then transformed into yeast together with a YAC/ BAC vector fitted with a Blasticidin resistance gene $(b s r)$. Recombination inside the yeast cell generated a concatenated

not bind CENP-B (Earnshaw et al. 1991) and lacks CENP-B boxes or from chromosome 21 type II $\alpha$ satellite, which lacks both a higher-order repeated structure and CENP-B boxes, both fail to yield HACs altogether (Harrington et al. 1997, Ikeno et al. 1998; Masumoto et al. 1998; Schueler et al. 2001; Grimes et al. 2002).

Ohzeki et al. (2002) systematically investigated the role of CENP-B in HAC formation by employing engineered $\alpha$-satellite sequences. Their studies revealed that

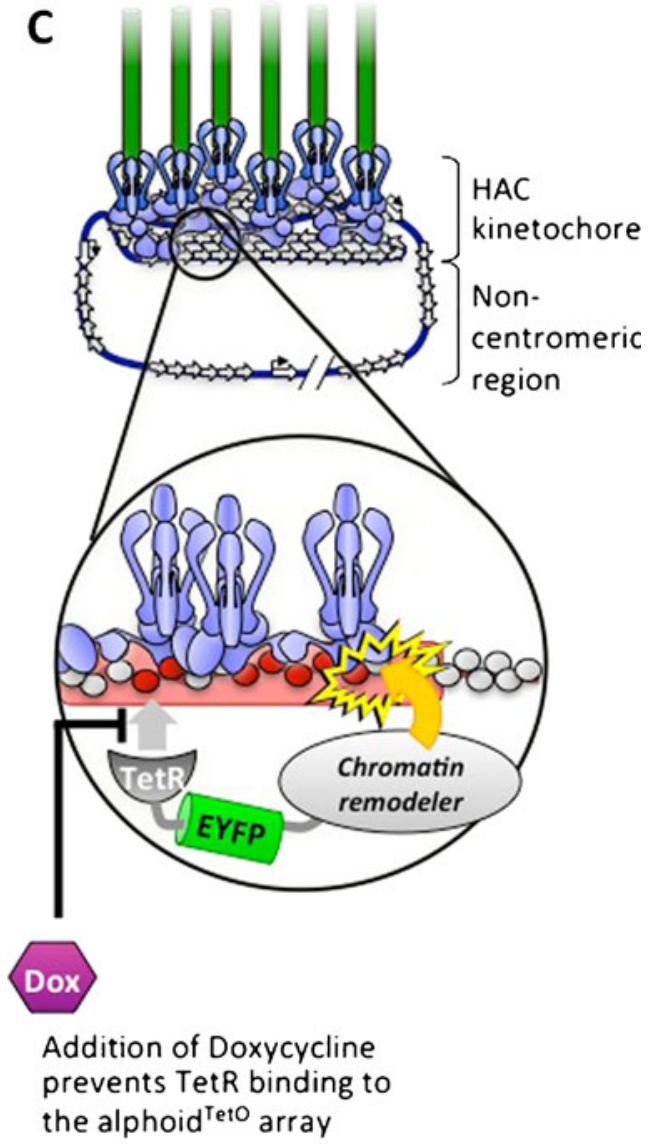

alphoid $^{\text {tetO }}$ array $40 \mathrm{~kb}$ long, with a backbone including the $b s r$ gene (Nakano et al. 2008). A recent study reports the detailed structural characterisation of the alphoid-tetO HAC (Kouprina 2012). b Mitotic chromosome spread from a cell line harbouring a mitotically stable HAC (white arrow). $\mathbf{c}$ HAC centrochromatin can be modified by tethering TetR-EYFP-(chromatin remodeler) fusion proteins. The tethering can be abolished if the growth medium is supplemented with doxycyline

de novo centromere formation only occurs on input $\alpha$-satellite with intact CENP-B boxes. HAC formation efficiency correlated with the relative density of CENP$\mathrm{B}$ boxes within the input array. Importantly, no HACs formed when CENP-B boxes were mutated to abrogate CENP-B binding, nor when intact CENP-B boxes were placed in non-alphoid, GC-rich DNA repeats.

The mechanism by which CENP-B facilitates HAC centromere formation is currently unknown. CENP-B 
was proposed to have a role in nucleosome phasing (Ando et al. 2002). However, more recent studies suggest that it has a dual role with respect to centromere function. CENP-B modulates local chromatin character in the context of $\alpha$-satellite input DNA, promoting CENP-A assembly during HAC formation, while creating a heterochromatin environment at integrated, inactive $\alpha$-satellite arrays (Okada et al. 2007). As discussed below, heterochromatin within the kinetochore is detrimental to maintenance of both CENP-A levels and kinetochore structure.

While these studies clearly indicate that CENP-B plays a key role in de novo HAC centromere formation, they beg the tantalising question about its endogenous role in the cell, which rarely if ever sees naked alphoid DNA and never assembles centromeres de novo. CENP$\mathrm{B}$ is conserved in several mammals (Sullivan and Glass 1991; Casola et al. 2008), yet is dispensable for chromosome segregation and kinetochore function in mice (Hudson et al. 1998; Perez-Castro et al. 1998; Kapoor et al. 1998) and at neocentromeres lacking functional CENP-B boxes (Voullaire et al. 1993; Choo 1997).

\section{Setting up new centromeres: chromatin matters}

The mysterious role of CENP-B in HAC formation raises the possibility that other chromatin factors, including histone posttranslational modifications, may have critical roles in HAC formation. In experiments in which DNA constructs are introduced into cells in the hopes of obtaining HACs, the most common outcome is that the transfected $\alpha$-satellite ends up integrated into the arm of a host chromosome (Ikeno et al. 1998; Masumoto et al. 1998; Nakano et al. 2008). Although not the desired outcome, these integrants offer the promise of acting as cryptic sites where centromere formation can potentially be nucleated de novo.

The role of active versus inactive chromatin in de novo centromere formation is extremely complex in human cells. For example, if the centromere of a presumptive HAC construct is flanked on both sides by actively expressed genes, this construct is inactive in HAC formation and only integrants are obtained (Nakashima et al. 2005). At least one of those flanking genes must be inactive to permit successful HAC formation.

Paradoxically, in the case of a HAC construct inserted into a chromosome arm, treatment of cells with the deacetylase inhibitor TSA (trichostatin A) can cause an increase in CENP-A levels at the integration site, with a subset of the integrated arrays gaining full centromeric activity (Nakano et al. 2003; Nakashima et al. 2005). As discussed below, TSA treatment can also rescue endogenous CENP-A assembly during knock-down of the Mis 18 complex, which is thought to "licence" the centromere for subsequent incorporation of CENP-A (Fujita et al. 2007; Maddox et al. 2007), suggesting that an open (acetylated) chromatin environment is required for centromere assembly and maintenance.

Ultimately, when one examines the structure of stable HACs, the HAC centrochromatin is close to chromatin domains that are enriched for heterochromatic marks. Thus, a balance must be maintained between an open, euchromatic signature and a flanking heterochromatin domain for stability. How the feedback and balance between these two antagonistic chromatin states occurs is currently unknown.

\section{Breaking the HAC formation barrier}

Established HACs are readily propagated in many different vertebrate cell types (Suzuki et al. 2006; Yamada et al. 2008; Cardinale et al. 2009; Iida et al. 2010), indicating that the mechanisms maintaining centromere identity and promoting kinetochore assembly are conserved across species. Indeed, in one study, the alphoid${ }^{\text {tetO }} \mathrm{HAC}$ was transferred by microcell-mediated fusion from human HT1080 cells to chicken DT40 cells, to Chinese Hamster CHO cells and back to HT1080 cells whilst being retrofitted with various markers and recombination sites (Iida et al. 2010). However, a perplexing phenomenon since the isolation of the first HACs was that de novo HAC formation appeared to be for all practical purposes limited to a single fibrosarcomaderived cell line, HT1080. A recent study has now provided a break-through in understanding, and importantly in overcoming, this limitation (Ohzeki et al. 2012).

Ohzeki and collaborators realised that HT1080 cells have much less robust centromeric heterochromatin than HeLa and several other cell types they examined. Once again, it appears that the underlying chromatin, and in particular a balance of histone $\mathrm{H} 3$ lysine- 9 methylation and acetylation associated with the $\alpha$-satellite domain, controls centromere specification. Alphoid arrays introduced into HeLa and several other mammalian cell lines rapidly assembled transient CENP-A domains. However, in contrast to HT1080, this CENP- 
A was lost over the next few days, accompanied by an inversely proportional increase in $\mathrm{H} 3 \mathrm{~K} 9 \mathrm{me} 3$ levels (Ohzeki et al. 2012). Knock-down of the H3K9 methyl-transferase Suv39h1 in HeLa cells promoted the assembly of CENP-A on the input alphoid array, suggesting that heterochromatin antagonizes the selfpropagation of a stable centromere.

This idea was explored by employing a chromosome 21-based alphoid ${ }^{\text {tetO }}$ array, and tethering a HAT (histone acetyl-transferase) to the transfected DNA during the HAC formation process in HeLa cells (Ohzeki et al. 2012). Binding of fusions of tetR to domains of either PCAF or p300 with HAT activity increased CENP-A deposition at the input alphoid $^{\text {tetO }}$ array. Furthermore, the CENP-A assemblies were stable and this approach promoted the formation of mitotically stable HACs assembling fully functional kinetochores for the first time in any human cell line other than HT1080 (Ohzeki et al. 2012) (Fig. 3).

The increase of CENP-A deposition as result of local acetylation during HAC formation agrees with initial studies in fission yeast that identified the Mis 18 complex as factor required for CENP-A loading (Hayashi et al. 2004). In humans, the Mis 18 complex associates with centromeres from anaphase into G1 (Fujita et al. 2007; Maddox et al. 2007), closely preceding the window of CENP-A loading. Although the underlying molecular mechanism remains to be determined, the CENP-A loading defect in Mis $18 \alpha$ knockdown conditions can be rescued by TSA, suggesting that nucleosome acetylation may be part of this licencing process (Fujita et al. 2007).

While exploring the relationship between centromere licensing and histone acetylation further, Ohzeki et al. (2012) were able to detect a transient increase in histone H3K9 acetylation levels at endogenous centromeres following release from a mitotic arrest. The increase in H3K9 acetylation levels appeared to correspond to the time window during which Mis 18 is implicated in centromere licensing. Strikingly, tethering of either HAT activity or Mis18 to a chromosomally integrated "inactive" alphoid ${ }^{\text {tetO }}$ array triggered the recruitment of centromeric proteins, and the generation of a functional, microtubule-binding kinetochore (Ohzeki et al. 2012). These data are consistent with the observation that when overexpressed, CENPA localizes ectopically along chromosome arms but fails to accumulate at heterochromatic sites in humans (Van Hooser et al. 2001) and suggest that histone acetylation is required for the de novo establishment of stable CENP-A domains.

\section{Targeted engineering of hac centrochromatin: many ways to disrupt a functional kinetochore}

The ability to target tetracycline repressor fusion chimeras to the alphoid ${ }^{\text {tetO }}$ array permits the specific manipulation of chromatin within a single functional centromere. This technology is still in its infancy but clearly offers an approach to dissecting the epigenetic factors that control centromere assembly and function.

\section{Heterochromatin kills kinetochores}

The alphoid ${ }^{\text {tetO }}$ HAC allows specific tests, for the first time in human cells, of how the underlying chromatin governs the function of established kinetochores. The first such study involved the tethering of a heterochromatin-seeding transcriptional repressor into the HAC kinetochore, resulting in a dramatic loss of kinetochore function over the course of several cell divisions (Nakano et al. 2008). On the molecular level, the loss of CENP-A correlated with a decrease in $\mathrm{H} 3 \mathrm{~K} 4 \mathrm{me} 2$ and an increase in H3K9me3 levels, paralleled by recruitment of HP $1 \alpha$ (heterochromatin protein $1 \alpha$ ) (Nakano et al. 2008). This study provided conclusive evidence that centromere chromatin state and kinetochore function are tightly inter-connected. A subsequent investigation (Cardinale et al. 2009) revealed that heterochromatin-associated loss of kinetochore structure was a hierarchical process, with CENP-C and CENP-H being rapidly displaced, and preceding a more gradual loss of CENP-A. In the same study, HAC kinetochore function collapsed at a time when CENP-A was still present at the centromere, confirming that CENP-A alone is not sufficient to drive kinetochore formation in an unfavourable chromatin context.

How may such unfavourable chromatin contexts trigger kinetochore malfunction? The HAC studies above are in agreement with CENP-A typically forming a distinctively stable component of centrochromatin (Ando et al. 2002, Foltz et al. 2006; Jansen et al. 2007; Hemmerich et al. 2008). In contrast, CENP-C shows dynamic exchange at the 
Fig. 3 Chromatin and de novo establishment of the CENP-A domain. a HAC generation assays are useful tools to identify the elements that contribute to de novo centromere formation. Additionally, most transfected arrays fail to form centromeres and integrate into endogenous chromosomes: subsequent manipulation of these 'dormant' arrays can allow them to gain centromere function. $\mathbf{b}$ HAC formation in HeLa cells is not efficient, leading to integrated HAC arrays that are wholly heterochromatic. When a histone acetyltransferase (HAT) is tethered to the alphoid ${ }^{\text {tetO }}$ array throughout the establishment assay, however, that barrier to de novo centromere formation is overcome and independent HACs are obtained. In an analogous manner, integrated alphoid $^{\text {tetO }}$ arrays can be reactivated by HAT tethering, and can acquire centromere function. c Mis18 localization to centromeres might affect the centromeres by recruiting HATs, leading to histone acetylation and creation of an open chromatin environment. This promotes transcription initiation and transcription through centromeric sequences. RNA polymerase II transit through nucleosomes causes histone displacement and chromatin remodelling. The relative importance of each of these factors to CENP-A assembly is still not clear
A Models for de novo centromere formation in HeLa cells:

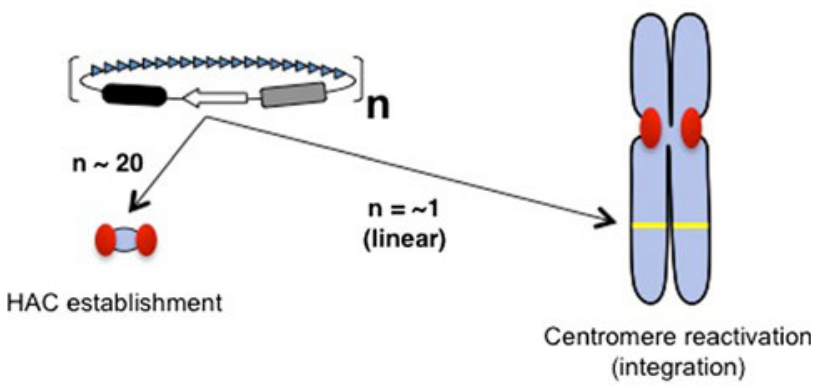

B HAT tethering to alphoid ${ }^{\text {Teto }}$ arrays promotes de novo CENP-A assembly
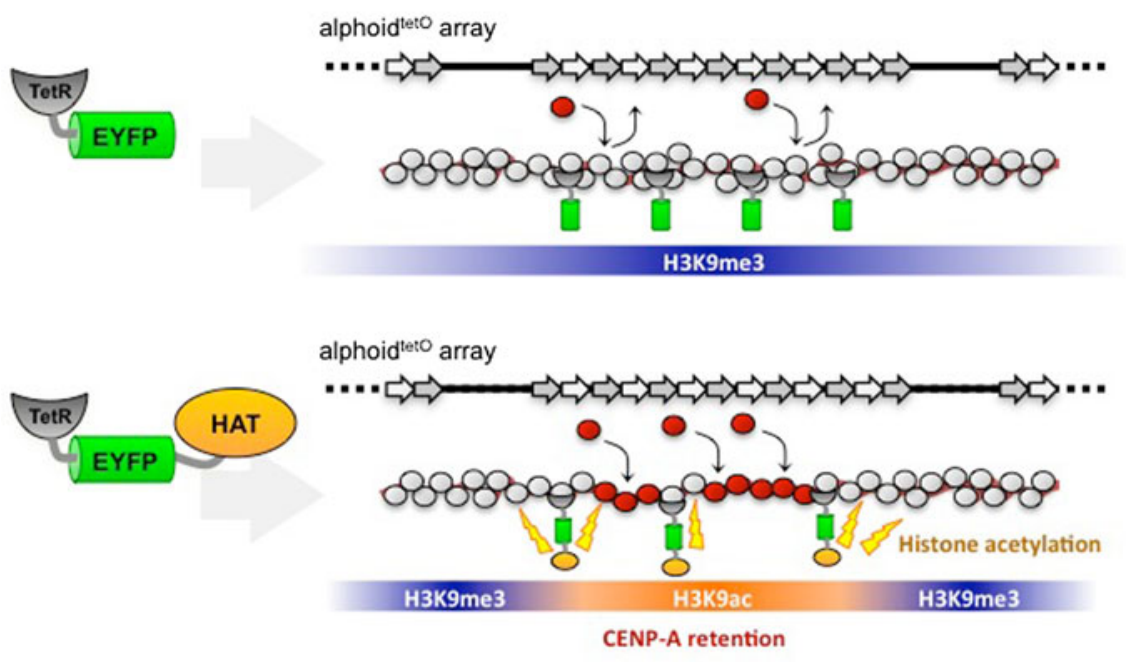

C

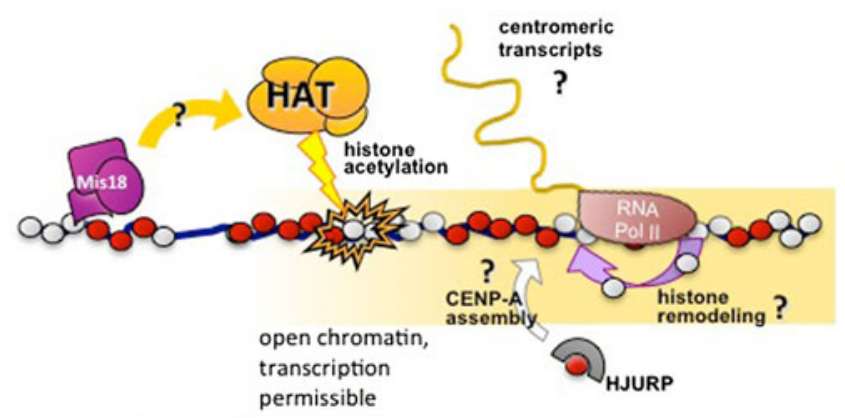

CENP-A

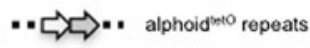

pre-kinetochore throughout interphase (Hemmerich et al. 2008) and associates with nucleosomes containing canonical histone $\mathrm{H} 3$ (Hori et al. 2008). Altering the post-translational modifications of $\mathrm{H} 3$-containing nucleosomes, or changing their conformational arrangement, might shift the equilibrium of CENP-C binding, thus causing a net loss of this molecule from the centromere. CENP-C provides an important link to the outer kinetochore (Tomkiel et al. 1994; Kwon et al. 2007; Liu et al. 2006; Przewloka et al. 2011; Screpanti et al. 2011). In light of its dynamics during interphase, an intriguing possibility is that CENP-C may perform a sentinel role, probing the chromatin state in the vicinity of CENP-A nucleosomes, thus aiding to restrict kinetochore assembly to regions with suitable centrochromatin state. 


\section{Centrochromatin and transcription}

The finding that an excessively heterochromatic environment is detrimental to kinetochore function originally came as a surprise, as centromeres had been classically regarded as heterochromatic regions. However, those data fit well with observations linking the centrochromatin domain to transcriptional activity. $\mathrm{H} 3 \mathrm{~K} 4 \mathrm{me} 2$, present within centrochromatin (Sullivan and Karpen 2004), is a modification typically found in the 5' region of poised as well as actively transcribed genes (Schneider et al. 2004; Barski et al. 2007), and is thus considered to mark a transcriptionally permissive chromatin environment. There is also direct evidence for satellite DNA transcription at centromeres in maize, mouse and humans (Topp et al. 2004; Kanellopoulou et al. 2005, Bergmann et al. 2011; Chan et al. 2012). Consistent with local transcriptional activity, hypermethylation of H3K36, a histone modification associated with elongating RNA polymerase II activity (Vakoc et al. 2006), was found to span the CENP-A nucleosome domain at human centromeres (Bergmann et al. 2011).

A recent study set out to test the consequences of depleting centromeric $\mathrm{H} 3 \mathrm{~K} 4 \mathrm{me} 2$ by tethering the H3K4me2-specific demethylase LSD1 into the alphoid $^{\text {tetO }}$ HAC kinetochore (Bergmann et al. 2011). LSD1 tethering resulted in a failure to recruit HJURP to the HAC, concomitant with a gradual decrease of centromeric CENP-A levels as a consequence of defective incorporation of newly synthesized CENP-A. These data provided strong support for the idea that individual histone modifications within centrochromatin stand upstream of CENP-A in the pathways culminating in maintenance of centromere identity and kinetochore function.

The loss of $\mathrm{H} 3 \mathrm{~K} 4$ methylation induced by tethering LSD1 into the alphoid ${ }^{\text {tetO }}$ centromere was coupled to a decline in transcription of the alphoid ${ }^{\text {tetO }}$ array. This repression of transcription was paralleled by a decrease in local H3K36 methylation and correlated with the net loss of CENP-A (Bergmann et al. 2011). Interestingly, knock-down of CHD1, which binds to methylated $\mathrm{H} 3 \mathrm{~K} 4$ and facilitates transcriptional elongation, also resulted in defective CENP-A maintenance (Okada et al. 2009). This supports the notion of a tight relationship between H3K4 methylation, transcriptional elongation and maintenance of centrochromatin.

Studies in yeast highlight the tight relationship between transcription and the associated chromatin state. Through its C-terminal domain, RNA polymerase II recruits a series of chromatin modifying activities in an elongation-stage specific manner. Near the 5' end of genes, Set1 and Dot1 methyltransferases hyper-methylate $\mathrm{H} 3 \mathrm{~K} 4$ and $\mathrm{H} 3 \mathrm{~K} 79$, respectively (Krogan et al. 2003a; Ng et al. 2003; Krogan et al. 2003b). Methylation of H3K4 is thought to provide an active "memory" regulating continued transcriptional activity (Muramoto et al. 2010; Kim and Buratowski 2009). Further downstream, recruitment of Set 2 introduces H3K36 hyper-methylation (Krogan et al. 2003b). This modification leads to suppression of local acetylation and is thought to suppress initiation of spurious transcripts within downstream regions (Carrozza et al. 2005; Keogh et al. 2005; Joshi and Struhl 2005).

Together, the results discussed above support a selfreinforcing model with respect to non-coding transcription and the functional state of HAC centrochromatin. In this model (Fig. 4), low levels of elongating polymerase at the centromere maintain the characteristic chromatin state via direct modulation of local histone modifications. The resulting over-all state of centrochromatin is permissive for the incorporation of CENP-A during mitotic exit. Although a recent study has demonstrated the presence of actively transcribing RNA polymerase II at mitotic kinetochores (Chan et al. 2012), the fact that CENP-A deposition normally happens following mitotic exit as determined in HeLa cells (Jansen et al. 2007) is in keeping with more conventional notions of the cell cycle regulation of Pol II transcription.

The role of transcription in promoting CENP-A assembly may either be conveyed by the presence of specific landmark histone modifications such as H3K4me2, or by RNA polymerase II activity and its associated factors. Notably, the FACT (facilitates chromatin transcription) complex associates with centrochromatin (Foltz et al. 2006, Izuta et al. 2006, Okada et al. 2009). FACT is thought to mediate transcription-associated nucleosome destabilization ahead of RNA polymerase as well as the subsequent re-integration of $\mathrm{H} 2 \mathrm{~A} / \mathrm{H} 2 \mathrm{~B}$ dimers during transcriptional elongation, thereby promoting the efficient progression of the transcriptional complex without the disruption of the underlying chromatin (Belotserkovskaya et al. 2003; Sims et al. 2004). Depletion of individual components of the FACT complex in chicken cells results in a defect in CENP-A maintenance comparable to that observed 

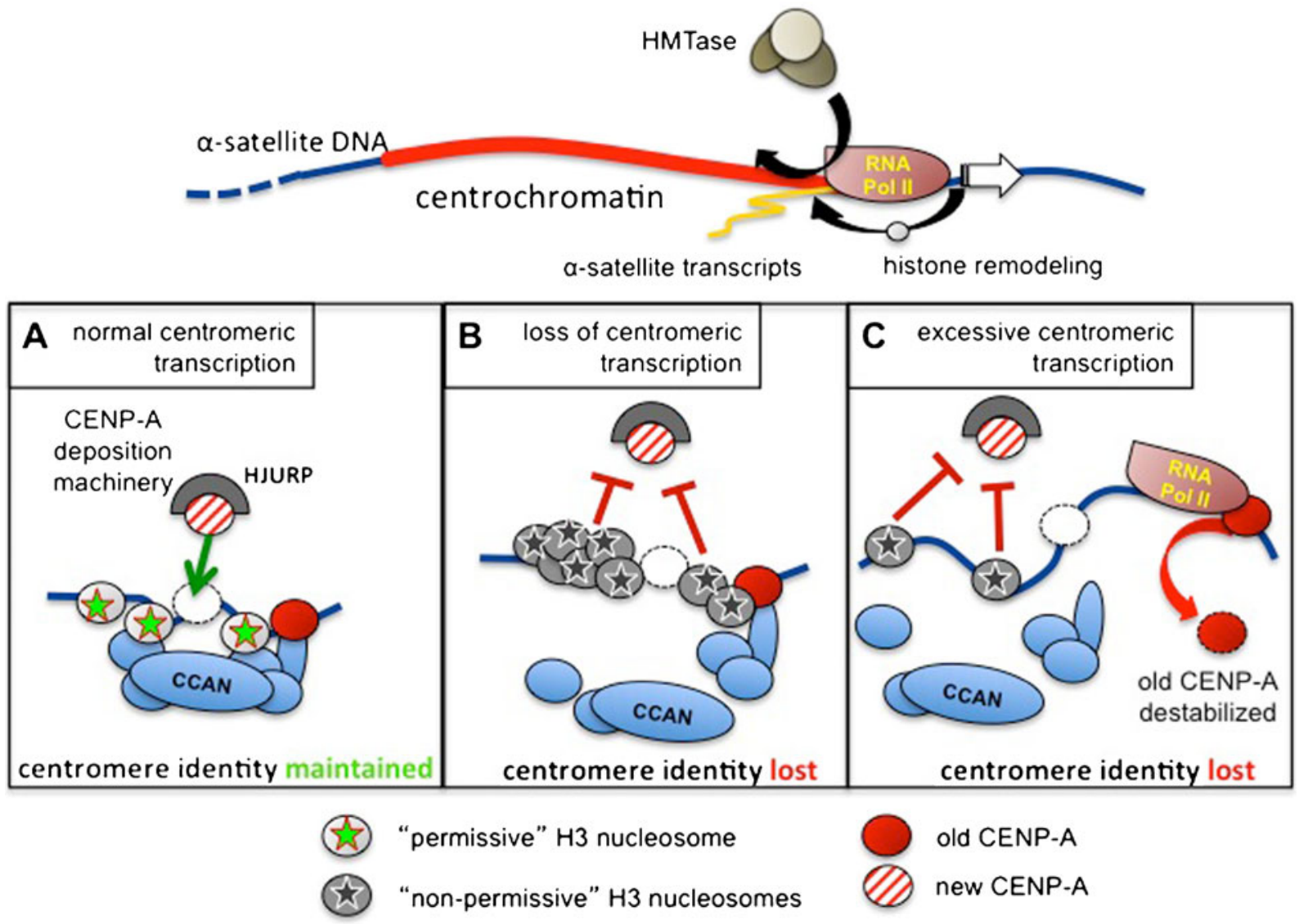

Fig. 4 A model for transcriptional maintenance of centrochromatin. Low levels of elongating RNA polymerase leave in their wake a characteristic chromatin landscape as a result of the recruitment of distinct histone methyltransferase complexes (HMTase). This permissive chromatin environment (A) facilitates directly or indirectly the deposition of newly synthesized CENP-A and the assembly of the CCAN complex, thus allowing for the propagation of a functional centromere through subsequent cell divisions.

following loss of CHD1 (Okada et al. 2009). Another chromatin remodelling factor, RSF, has also been implicated in the stabilisation of CENP-A association with centrochromatin (Perpelescu et al. 2009).

Both the structure of the transcription units and the regulation of centromeric transcription remain critical unanswered questions. Transcription near the periphery of endogenous centromeres may initiate at promoter-containing elements such as LINEs or LTRs interspersed within the more divergent satellite II regions, as previously proposed (Wong and Choo 2004) and demonstrated (Topp et al. 2004, Carone et al. 2009) by others. In light of the A/T-richness of centromeres, cryptic transcription initiation sites within
B Transcriptional repression results in a failure to maintain this permissive chromatin state and the loss of CENP-A incorporation. In the case of heterochromatinization, certain histone modifications or chromatin conformations may further result in defective assembly of the CCAN complex. Excessive transcriptional activity (C) on the other hand is disruptive to CENP-A chromatin, possibly due to the destabilization or eviction of CENP-A nucleosomes through the elongating polymerase machinery

specific $\alpha$-satellite monomers themselves could possibly account for sporadic transcriptional initiation. This sporadic transcriptional initiation could be also linked with replication of the long centromeric repeats. Sequence read lengths of thousands or even tens of thousands basepairs may reveal unrecognised sequence ambiguities in centromeric DNA that would allow for the identification of promoter-like consensus sequences, as well as for the more precise mapping of centromeric RNA sequencing reads. The advent of third generation high throughput sequencing approaches aiming at longer read lengths may thus provide the technology to address this question in the future. 


\section{Transcription at the centromere:} it's all in the balance

Just as excessive heterochromatin is incompatible with centromere function, excessive transcription also appears to be detrimental. Strong transcriptional bombardment of the centromere in yeast inactivated the kinetochore, creating the first conditional centromere (Hill and Bloom 1987). Similarly, targeting of a strong transcriptional activator into the alphoid ${ }^{\text {tetO }} \mathrm{HAC}$ caused a loss of HAC kinetochore function in a fraction of cells (Nakano et al. 2008). These data suggested that a balance between euchromatin and heterochromatin might be critical for the maintenance of centromere identity.

A recent study employed the alphoid ${ }^{\text {tetO }}$ HAC system to specifically address the question of how transcriptionally permissive chromatin might influence kinetochore maintenance (Bergmann et al. 2012). Tethering a mild transcriptional activator (the minimal activation domain of p65) to the HAC centromere revealed a remarkable degree of plasticity of kinetochores towards the underlying chromatin. Despite the induction of local histone H3K9 hyper-acetylation and elevated RNA polymerase activity, levels of CENP-A or CENP-C at the HAC centromere were virtually unaffected. Indeed, these engineered HACs retained a fully functional kinetochore and were stably propagated through several cell divisions.

In stark contrast was the outcome of tethering the more potent transcriptional activator, VP16. While introducing levels of histone H3K9 hyper-acetylation comparable to those seen after tethering p65 at the HAC, the transcription of the alphoid ${ }^{\text {tetO }}$ array was significantly ( $>15$-fold) higher following targeting by VP16, raising its level to near that of house-keeping genes or the Blasticidin-resistance marker gene. This resulted in a rapid inactivation of the HAC kinetochore due not only to a complete block of CENP-A loading, but also to the specific and rapid stripping of pre-assembled CENP-A from the HAC kinetochore (Bergmann et al. 2012).

Studies with the alphoid ${ }^{\text {tetO }} \mathrm{HAC}$ to date suggest that functional centrochromatin requires a tightly regulated balance of local transcriptional activity (Fig. 4). The establishment and maintenance of a chromatin environment permissive for centromere identity thus adds an additional layer of regulation to the specification and maintenance of kinetochore assembly.

\section{Outlook}

HACs are proving to be an invaluable and highly versatile model system for the study of centrochromatin and its impact on kinetochore structure and function in human cells. In particular, the design of synthetic higher-order $\alpha$-satellite arrays has generated a range of data that elegantly confirm the long-standing hypothesis of the "epigenetic" chromatin environment being integral to centromere identity.

The alphoid ${ }^{\text {tetO }}$ HAC offers the potential to further dissect the requirement of individual histone modifications for the formation and maintenance of inner kinetochore structure. Next-generation synthetic HACs that allow for the regulated, simultaneous tethering of more than one chromatin effector at a time and construction of HACs bearing synthetic pericentromeric heterochromatin flanking the kinetochore should further increase our ability to probe the centrochromatin state.

A key question that arises from the current data is the precise role of transcription in the maintenance of centrochromatin and how the role of HAC centromere transcription is applicable to endogenous centromeres. Is local RNA polymerase activity an active or a passive contributor towards centromere identity? In other words, is it the transcription or the resulting chromatin modifications that foster the sustained deposition of CENP-A? One recent study strongly implicates a role of kinetochore-linked transcription during mitosis (Chan et al. 2012), but this awaits confirmation and expansion. A comparable conundrum, which should technically be easier to address, is whether centromeric RNA is merely a by-product of a process shaping local chromatin architecture, or if perhaps - as in yeast (Pidoux and Allshire 2005) - these RNAs have a direct role in the maintenance of certain aspects of centromere structure.

Acknowledgments J.H.B. is supported by a DAAD postdoctoral fellowship. N.M.M. is supported by a Ph.D. studentship of the Fundação para a Ciência e Tecnologia, Portugal. Work in the VL lab is funded by the Intramural Research Program of the NIH, National Cancer Institute, Center for Cancer Research, USA. Work in the HM lab is funded by the Ministry of Education, Culture, Sports, Science and Technology of Japan, and the Kazusa DNA Research Institute Foundation. Work in the WCE lab is funded by The Wellcome Trust, of which WCE is a Principal Research Fellow [grant number 073915]. The Wellcome Trust Centre for Cell Biology is supported by core grant numbers 077707 and 092076. 


\section{References}

Alabert C, Groth A (2012) Chromatin replication and epigenome maintenance. Nat Rev Mol Cell Biol 13:153-167

Allshire RC, Karpen GH (2008) Epigenetic regulation of centromeric chromatin: old dogs, new tricks? Nat Rev Genet 9:923-937

Alonso A, Mahmood R, Li S, Cheung F, Yoda K, Warburton PE (2003) Genomic microarray analysis reveals distinct locations for the CENP-A binding domains in three human chromosome 13q32 neocentromeres. Hum Mol Genet 12:2711-2721

Alonso A, Fritz B, Hasson D, Abrusan G, Cheung F, Yoda K, Radlwimmer B, Ladurner AG, Warburton PE (2007) Co-localization of CENP-C and CENP-H to discontinuous domains of CENP-A chromatin at human neocentromeres. Genome Biol 8:R148

Ando S, Yang H, Nozaki N, Okazaki T, Yoda K (2002) CENP$\mathrm{A}$, -B, and -C chromatin complex that contains the I-type alpha-satellite array constitutes the prekinetochore in $\mathrm{HeLa}$ cells. Mol Cell Biol 22:2229-2241

Barski A, Cuddapah S, Cui K, Roh TY, Schones DE, Wang Z, Wei G, Chepelev I, Zhao K (2007) High-resolution profiling of histone methylations in the human genome. Cell 129:823-837

Basu J, Willard HF (2005) Artificial and engineered chromosomes: non-integrating vectors for gene therapy. Trends in Mol Med 11:251-258

Belotserkovskaya R, Oh S, Bondarenko VA, Orphanides G, Studitsky VM, Reinberg D (2003) FACT facilitates transcription-dependent nucleosome alteration. Science 301:1090-1093

Berger SL (2007) The complex language of chromatin regulation during transcription. Nature 447:407-412

Bergmann JH, Rodriguez MG, Martins NM, Kimura H, Kelly DA, Masumoto H, Larionov V, Jansen LE, Earnshaw WC (2011) Epigenetic engineering shows $\mathrm{H} 3 \mathrm{~K} 4 \mathrm{me} 2$ is required for HJURP targeting and CENP-A assembly on a synthetic human kinetochore. EMBO J 30:328-340

Bergmann JH, Jakubsche JN, Martins NM, Kagansky A, Nakano M, Kimura H, Kelly DA, Turner BM, Masumoto H, Larionov V, Earnshaw WC (2012) Epigenetic engineering: histone $\mathrm{H} 3 \mathrm{~K} 9$ acetylation is compatible with kinetochore structure and function. J Cell Sci Suppl 125:411-421

Black BE, Bassett EA (2008) The histone variant CENP-A and centromere specification. Curr Opin Cell Biol 20:91-100

Blasco MA (2007) The epigenetic regulation of mammalian telomeres. Nat Rev Genet 8:299-309

Blower MD, Sullivan BA, Karpen GH (2002) Conserved organization of centromeric chromatin in flies and humans. Dev Cell 2:319-330

Burke DT, Carle GF, Olson MV (1987) Cloning of large segments of exogenous DNA into yeast by means of artificial chromosome vectors. Science 236:806-812

Cardinale S, Bergmann JH, Kelly D, Nakano M, Valdivia MM, Kimura H, Masumoto H, Larionov V, Earnshaw WC (2009) Hierarchical inactivation of a synthetic human kinetochore by a chromatin modifier. Mol. Biol, Cell

Carone DM, Longo MS, Ferreri GC, Hall L, Harris M, Shook N, Bulazel KV, Carone BR, Obergfell C, O'Neill MJ, O'Neill RJ
(2009) A new class of retroviral and satellite encoded small RNAs emanates from mammalian centromeres. Chromosoma 118:113-125

Carroll CW, Silva MC, Godek KM, Jansen LE, Straight AF (2009) Centromere assembly requires the direct recognition of CENP-A nucleosomes by CENP-N. Nat Cell Biol 11:896-902

Carrozza MJ, Li B, Florens L, Suganuma T, Swanson SK, Lee KK, Shia WJ, Anderson S, Yates J, Washburn MP, Workman JL (2005) Histone H3 methylation by Set2 directs deacetylation of coding regions by $\mathrm{Rpd} 3 \mathrm{~S}$ to suppress spurious intragenic transcription. Cell 123:581-592

Casola C, Hucks D, Feschotte C (2008) Convergent domestication of pogo-like transposases into centromere-binding proteins in fission yeast and mammals. Mol Biol Evol 25:29-41

Chan FL, Marshall OJ, Saffery R, Kim BW, Earle E, Choo KH, Wong LH (2012) Active transcription and essential role of RNA polymerase II at the centromere during mitosis. Proc Natl Acad Sci U S A 109:1979-1984

Cheeseman IM, Desai A (2008) Molecular architecture of the kinetochore-microtubule interface. Nat Rev Mol Cell Biol 9:33-46

Choo KH (1997) Centromere DNA dynamics: latent centromeres and neocentromere formation. Am J Hum Genet 61:1225-1233

Choo KH, Vissel B, Nagy A, Earle E, Kalitsis P (1991) A survey of the genomic distribution of alpha satellite DNA on all human chromosomes, and derivation of a new consensus sequence. Nucleic Acids Res 19:1179-1182

Chueh AC, Wong LH, Wong N, Choo KH (2005) Variable and hierarchical size distribution of L1-retroelement-enriched CENP-A clusters within a functional human neocentromere. Hum Mol Genet 14:85-93

Clarke L, Carbon J (1980) Isolation of a yeast centromere and construction of functional small circular chromosomes. Nature 287:504-509

Cleveland DW, Mao Y, Sullivan KF (2003) Centromeres and kinetochores: from epigenetics to mitotic checkpoint signaling. Cell 112:407-421

Dinant C, Houtsmuller AB, Vermeulen W (2008) Chromatin structure and DNA damage repair. Epigenetics Chromatin 1:9

du Sart D, Cancilla MR, Earle E, Mao JI, Saffery R, Tainton KM, Kalitsis P, Martyn J, Barry AE, Choo KH (1997) A functional neo-centromere formed through activation of a latent human centromere and consisting of non-alphasatellite DNA. Nat Genet 16:144-153

Earnshaw WC, Migeon B (1985) A family of centromere proteins is absent from the latent centromere of a stable isodicentric chromosome. Chromosoma (Berl) 92:290-296

Earnshaw WC, Rothfield N (1985) Identification of a family of human centromere proteins using autoimmune sera from patients with scleroderma. Chromosoma (Berl) 91:313321

Earnshaw WC, Sullivan KF, Machlin PS, Cooke CA, Kaiser DA, Pollard TD, Rothfield NF, Cleveland DW (1987) Molecular cloning of cDNA for CENP-B, the major human centromere autoantigen. J Cell Biol 104:817-829

Earnshaw WC, Ratrie H, Stetten G (1989) Visualization of centromere proteins CENP-B and CENP-C on a stable 
dicentric chromosome in cytological spreads. Chromosoma (Berl) 98:1-12

Earnshaw WC, Bernat RL, Cooke CA, Rothfield NF (1991) Role of the centromere/ kinetochore in cell cycle control. Cold Spring Harbor Symp Quant Biol 56:675-685

Ebersole TA, Ross A, Clark E, McGill N, Schindelhauer D, Cooke H, Grimes B (2000) Mammalian artificial chromosome formation from circular alphoid input DNA does not require telomere repeats. Hum Mol Genet 9:1623-1631

Ebersole T, Okamoto Y, Noskov VN, Kouprina N, Kim JH, Leem SH, Barrett JC, Masumoto H, Larionov V (2005) Rapid generation of long synthetic tandem repeats and its application for analysis in human artificial chromosome formation. Nucleic Acids Res 33:e130

Foltz DR, Jansen LE, Black BE, Bailey AO, Yates JR, Cleveland DW (2006) The human CENP-A centromeric nucleosomeassociated complex. Nat Cell Biol 8:458-469

Fujita Y, Hayashi T, Kiyomitsu T, Toyoda Y, Kokubu A, Obuse C, Yanagida M (2007) Priming of centromere for CENP-A recruitment by human hMis18alpha, hMis18beta, and M18BP1. Dev Cell 12:17-30

Goshima G, Kiyomitsu T, Yoda K, Yanagida M (2003) Human centromere chromatin protein hMis12, essential for equal segregation, is independent of CENP-A loading pathway. J Cell Biol 160:25-39

Grimes BR, Rhoades AA, Willard HF (2002) Alpha-satellite DNA and vector composition influence rates of human artificial chromosome formation. Mol Ther 5:798-805

Harrington JJ, van Bokkelen G, Mays RW, Gustashaw K, Willard HF (1997) Formation of de novo centromeres and construction of first-generation human artificial microchromosomes. Nat Genet 15:345-355

Hayashi T, Fujita Y, Iwasaki O, Adachi Y, Takahashi K, Yanagida M (2004) Mis16 and Mis 18 are required for CENP-A loading and histone deacetylation at centromeres. Cell 118:715-729

Hemmerich P, Weidtkamp-Peters S, Hoischen C, Schmiedeberg L, Erliandri I, Diekmann S (2008) Dynamics of inner kinetochore assembly and maintenance in living cells. J Cell Biol 180:1101-1114

Heun P, Erhardt S, Blower MD, Weiss S, Skora AD, Karpen GH (2006) Mislocalization of the drosophila centromerespecific histone CID promotes formation of functional ectopic kinetochores. Dev Cell 10:303-315

Hill A, Bloom K (1987) Genetic manipulation of centromere function. Mol Cell Biol 7:2397-2405

Hori T, Amano M, Suzuki A, Backer CB, Welburn JP, Dong Y, McEwen BF, Shang WH, Suzuki E, Okawa K, Cheeseman IM, Fukagawa T (2008) CCAN makes multiple contacts with centromeric DNA to provide distinct pathways to the outer kinetochore. Cell 135:1039-1052

Huang J, Berger SL (2008) The emerging field of dynamic lysine methylation of non-histone proteins. Curr Opin Genet Dev 18:152-158

Hudson D, Fowler KJ, Earle E, Saffery R, Kalitsis P, Trowell H, Hill J, Wreford NG, de Kretser DM, Cancilla MR, Howman E, Hii L, Cutts SM, Irvine DV, Choo KHA (1998) Centromere protein B null mice are mitotically and meiotically normal but have lower body and testis weights. J Cell Biol 141:309-319

Iida Y, Kim JH, Kazuki Y, Hoshiya H, Takiguchi M, Hayashi M, Erliandri I, Lee HS, Samoshkin A, Masumoto H,
Earnshaw WC, Kouprina N, Larionov V, Oshimura M (2010) Human artificial chromosome with a conditional centromere for gene delivery and gene expression. DNA Res 17:293-301

Ikeno M, Masumoto H, Okazaki T (1994) Distribution of CENP-B boxes reflected in CREST centromere antigenic sites on long-range alpha-satellite DNA arrays of human chromosome 21. Hum Mol Genet 3:1245-1257

Ikeno M, Grimes B, Okazaki T, Nakano M, Saitoh K, Hoshino H, McGill NI, Cooke H, Masumoto H (1998) Construction of YAC-based mammalian artificial chromosomes. Nat Biotechnol 16:431-439

Izuta H, Ikeno M, Suzuki N, Tomonaga T, Nozaki N, Obuse C, Kisu Y, Goshima N, Nomura F, Nomura N, Yoda K (2006) Comprehensive analysis of the ICEN (Interphase Centromere Complex) components enriched in the CENP-A chromatin of human cells. Genes Cells 11:673-684

Jansen LE, Black BE, Foltz DR, Cleveland DW (2007) Propagation of centromeric chromatin requires exit from mitosis. $\mathrm{J}$ Cell Biol 176:795-805

Joshi AA, Struhl K (2005) Eaf3 chromodomain interaction with methylated H3-K36 links histone deacetylation to Pol II elongation. Mol Cell 20:971-978

Kanellopoulou C, Muljo SA, Kung AL, Ganesan S, Drapkin R, Jenuwein T, Livingston DM, Rajewsky K (2005) Dicerdeficient mouse embryonic stem cells are defective in differentiation and centromeric silencing. Genes Dev 19:489-501

Kapoor M, Montes de Oca Luna R, Liu G, Lozano G, Cummings C, Mancini M, Ouspenski I, Brinkley BR, May GS (1998) The cenpB gene is not essential in mice. Chromosoma 107:570-576

Karpen GH, Allshire RC (1997) The case for epigenetic effects on centromere identity and function. Trends Genet 13:489-496

Keogh MC, Kurdistani SK, Morris SA, Ahn SH, Podolny V, Collins SR, Schuldiner M, Chin K, Punna T, Thompson NJ, Boone C, Emili A, Weissman JS, Hughes TR, Strahl BD, Grunstein M, Greenblatt JF, Buratowski S, Krogan NJ (2005) Cotranscriptional set2 methylation of histone H3 lysine 36 recruits a repressive Rpd3 complex. Cell 123:593-605

Kim T, Buratowski S (2009) Dimethylation of H3K4 by Set1 recruits the Set3 histone deacetylase complex to $5^{\prime}$ transcribed regions. Cell 137:259-272

Kouprina N, Samoshkin A, Erliandri I, Nakano M, Lee H-S, $\mathrm{Fu} \mathrm{H}$, Aladjem MI, Masumoto H, Earnshaw WC, Larionov V (2012) Organization of synthetic alphoid DNA array in human artificial chromosome (HAC) with a conditional centromere. ACS Synthetic Biology (in press)

Krogan NJ, Dover J, Wood A, Schneider J, Heidt J, Boateng MA, Dean K, Ryan OW, Golshani A, Johnston M, Greenblatt JF, Shilatifard A (2003a) The Pafl complex is required for histone H3 methylation by COMPASS and Dotlp: linking transcriptional elongation to histone methylation. Mol Cell 11:721-729

Krogan NJ, Kim M, Tong A, Golshani A, Cagney G, Canadien V, Richards DP, Beattie BK, Emili A, Boone C, Shilatifard A, Buratowski S, Greenblatt J (2003b) Methylation of histone $\mathrm{H} 3$ by Set 2 in Saccharomyces cerevisiae is linked to transcriptional elongation by RNA polymerase II. Mol Cell Biol 23:4207-4218 
Kwon MS, Hori T, Okada M, Fukagawa T (2007) CENP-C is involved in chromosome segregation, mitotic checkpoint function, and kinetochore assembly. Mol Biol Cell 18:21552168

Liu ST, Rattner JB, Jablonski SA, Yen TJ (2006) Mapping the assembly pathways that specify formation of the trilaminar kinetochore plates in human cells. J Cell Biol 175:41-53

Lo AW, Craig JM, Saffery R, Kalitsis P, Irvine DV, Earle E, Magliano DJ, Choo KH (2001) A 330kb CENP-A binding domain and altered replication timing at a human neocentromere. EMBO J 20:2087-2096

Maddox PS, Hyndman F, Monen J, Oegema K, Desai A (2007) Functional genomics identifies a Myb domain-containing protein family required for assembly of CENP-A chromatin. J Cell Biol 176:757-763

Masumoto H, Masukata H, Muro Y, Nozaki N, Okazaki T (1989) A human centromere antigen (CENP-B) interacts with a short specific sequence in alphoid DNA, a human centromeric satellite. J Cell Biol 109:1963-1973

Masumoto H, Ikeno M, Nakano M, Okazaki T, Grimes B, Cooke H, Suzuki N (1998) Assay of centromere function using a human artificial chromosome. Chromosoma 107:406-416

Mendiburo MJ, Padeken J, Fulop S, Schepers A, Heun P (2012) Drosophila CENH3 is sufficient for centromere formation. Science 334:686-990

Merry DW, Pathak S, Hsu TC, Brinkley BR (1985) Antikinetochore antibodies: use as probes for inactive centromeres. Am J Hum Genet 37:425-430

Muramoto T, Muller I, Thomas G, Melvin A, Chubb JR (2010) Methylation of $\mathrm{H} 3 \mathrm{~K} 4$ is required for inheritance of active transcriptional states. Curr Biol 20:397-406

Murray AW, Szostak JW (1983) Construction of artificial chromosomes in yeast. Nature 305:189-193

Nakano M, Okamoto Y, Ohzeki J, Masumoto H (2003) Epigenetic assembly of centromeric chromatin at ectopic alpha-satellite sites on human chromosomes. J Cell Sci 116:4021-4034

Nakano M, Cardinale S, Noskov VN, Gassmann R, Vagnarelli P, Kandels-Lewis S, Larionov V, Earnshaw WC, Masumoto H (2008) Inactivation of a human kinetochore by specific targeting of chromatin modifiers. Dev Cell 14:507-522

Nakashima H, Nakano M, Ohnishi R, Hiraoka Y, Kaneda Y, Sugino A, Masumoto H (2005) Assembly of additional heterochromatin distinct from centromere-kinetochore chromatin is required for de novo formation of human artificial chromosome. J Cell Sci 118:5885-5898

Ng HH, Robert F, Young RA, Struhl K (2003) Targeted recruitment of Set1 histone methylase by elongating Pol II provides a localized mark and memory of recent transcriptional activity. Mol Cell 11:709-719

Nishino T, Takeuchi K, Gascoigne KE, Suzuki A, Hori T, Oyama T, Morikawa K, Cheeseman IM, Fukagawa T (2012) CENP-T-W-S-X forms a unique centromeric chromatin structure with a histone-like fold. Cell 148:487-501

Oegema K, Desai A, Rybina S, Kirkham M, Hyman AA (2001) Functional analysis of kinetochore assembly in Caenorhabditis elegans. J Cell Biol 153:1209-1226

Ohzeki J, Nakano M, Okada T, Masumoto H (2002) CENP$\mathrm{B}$ box is required for de novo centromere chromatin assembly on human alphoid DNA. J Cell Biol 159:765775
Ohzeki J, Bergmann JH, Kouprina N, Noskov VN, Nakano M, Kimura H, Earnshaw WC, Larionov V, Masumoto $\mathrm{H}$ (2012) Breaking the HAC barrier: histone H3K9 acetyl/ methyl balance regulates CENP-A assembly. EMBO J 31:2391-2402

Okada T, Ohzeki J, Nakano M, Yoda K, Brinkley WR, Larionov V, Masumoto H (2007) CENP-B controls centromere formation depending on the chromatin context. Cell 131:1287-1300

Okada M, Okawa K, Isobe T, Fukagawa T (2009) CENP-Hcontaining complex facilitates centromere deposition of CENP-A in cooperation with FACT and CHD1. Mol Biol Cell 20:3986-3995

Okamoto Y, Nakano M, Ohzeki J, Larionov V, Masumoto H (2007) A minimal CENP-A core is required for nucleation and maintenance of a functional human centromere. EMBO J 26:1279-1291

Palmer DK, Margolis RL (1987) A 17-kD centromere protein (CENP-A) copurifies with nucleosome core particles and with histones. J Cell Biol 104:805-815

Palmer DK, O'Day K, le Trong H, Charbonneau H, Margolis RL (1991) Purification of the centromeric protein CENP-A and demonstration that it is a centromere specific histone. Proc Nat Acad Sci (USA) 88:3734-3738

Perez-Castro AV, Shamanski FL, Meneses JJ, Lovato TL, Vogel KG, Moyzis RK, Pedersen R (1998) Centromeric Protein B null mice are viable with no apparent abnormalities. Dev Biol 201:135-143

Perpelescu M, Nozaki N, Obuse C, Yang H, Yoda K (2009) Active establishment of centromeric CENP-A chromatin by RSF complex. J Cell Biol 185:397-407

Pidoux AL, Allshire RC (2005) The role of heterochromatin in centromere function. Philos Trans R Soc Lond B Biol Sci 360:569-579

Przewloka MR, Venkei Z, Bolanos-Garcia VM, Debski J, Dadlez M, Glover DM (2011) CENP-C is a structural platform for kinetochore assembly. Curr Biol 21:399-405

Ribeiro SA, Vagnarelli P, Dong Y, Hori T, McEwen BF, Fukagawa T, Flors C, Earnshaw WC (2010) A super-resolution map of the vertebrate kinetochore. Proc Natl Acad Sci U S A 107:10484-10489

Saffery R, Irvine DV, Griffiths B, Kalitsis P, Wordeman L, Choo KH (2000) Human centromeres and neocentromeres show identical distribution patterns of $>20$ functionally important kinetochore-associated proteins. Hum Mol Genet 9:175-185

Schneider R, Bannister AJ, Myers FA, Thorne AW, CraneRobinson C, Kouzarides T (2004) Histone H3 lysine 4 methylation patterns in higher eukaryotic genes. Nat Cell Biol 6:73-77

Schueler MG, Higgins AW, Rudd MK, Gustashaw K, Willard HF (2001) Genomic and genetic definition of a functional human centromere. Science 294:109-115

Screpanti E, de Antoni A, Alushin GM, Petrovic A, Melis T, Nogales E, Musacchio A (2011) Direct binding of Cenp-C to the Mis12 complex joins the inner and outer kinetochore. Curr Biol 21:391-398

Sims RJ, Belotserkovskaya R 3rd, Reinberg D (2004) Elongation by RNA polymerase II: the short and long of it. Genes Dev 18:2437-2468

Spange S, Wagner T, Heinzel T, Kramer OH (2009) Acetylation of non-histone proteins modulates cellular signalling at multiple levels. Int J Biochem Cell Biol 41:185-198 
Stinchcomb DT, Struhl K, Davis RW (1979) Isolation and characterisation of a yeast chromosomal replicator. Nature 282:39-43

Sugata N, Li S, Earnshaw WC, Yen TJ, Yoda K, Masumoto H, Munekata E, Warburton PE, Todokoro K (2000) Human CENP-H multimers colocalize with CENP-A and CENP-C at active centromere-kinetochore complexes. Hum Mol Genet 9:2919-2926

Sullivan KF, Glass CA (1991) CENP-B is a highly conserved mammalian centromere protein with homology to the helixloop-helix family of proteins. Chromosoma (Berl) 100:360370

Sullivan BA, Karpen GH (2004) Centromeric chromatin exhibits a histone modification pattern that is distinct from both euchromatin and heterochromatin. Nat Struct Mol Biol 11:10761083

Sullivan BA, Schwartz S (1995) Identification of centromeric antigens in dicentric robertsonian translocations: CENP-C and CENP-E are necessary components of functional centromeres. Hum Mol Genet 4:2189-2197

Sullivan KF, Hechenberger M, Masri K (1994) Human CENP-A contains a histone $\mathrm{H} 3$ related histone fold domain that is required for targeting to the centromere. J Cell Biol 127:581-192

Suzuki N, Nishii K, Okazaki T, Ikeno M (2006) Human artificial chromosomes constructed using the bottom-up strategy are stably maintained in mitosis and efficiently transmissible to progeny mice. J Biol Chem 281:26615-26623

Szostak JW, Blackburn EH (1982) Cloning yeast telomeres on linear plasmid vectors. Cell 29:245-255

Tomkiel JE, Cooke CA, Saitoh H, Bernat RL, Earnshaw WC (1994) CENP-C is required for maintaining proper kinetochore size and for a timely transition to anaphase. J Cell Biol 125:531-545

Topp CN, Zhong CX, Dawe RK (2004) Centromere-encoded RNAs are integral components of the maize kinetochore. Proc Natl Acad Sci U S A 101:15986-15991

Tsuduki T, Nakano M, Yasuoka S, Masumoto H (2006) An artificially constructed de novo human chromosome behaves almost identically to its natural counterpart during metaphase and anaphase in living cells. Mol Cell Biol 26:7682-7695
Vafa O, Sullivan KF (1997) Chromatin containing CENP-A and $\alpha$-satellite DNA is a major component of the inner kinetochore plate. Curr Biol 7:897-900

Vakoc CR, Sachdeva MM, Wang H, Blobel GA (2006) Profile of histone lysine methylation across transcribed mammalian chromatin. Mol Cell Biol 26:9185-9195

van Hooser A, Ouspenski A II, Gregson HC, Starr DA, Yen TJ, Goldberg ML, Yokomori K, Earnshaw WC, Sullivan K, Brinkley BR (2001) Specification of kinetochore-forming chromatin by the histone H3 variant CENP-A. J Cell Sci 114:3529-3542

Voullaire LE, Slater HR, Petrovic V, Choo KH (1993) A functional marker centromere with no detectible alpha-satellite, satellite III, or CENP-B protein: activation of a latent centromere? Am J Hum Genet 52:1153-1163

Warburton PE (2001) Epigenetic analysis of kinetochore assembly on variant human centromeres. Trends Genet 17:243247

Warburton PE, Cooke C, Bourassa S, Vafa O, Sullivan BA, Stetten G, Gimelli G, Warburton D, Tyler-Smith C, Sullivan KF, Poirier GG, Earnshaw WC (1997) Immunolocalization of CENP-A suggests a distinct nucleosome structure at the inner kinetochore plate of active centromeres. Curr Biol 7:901-904

Waye JS, Willard H (1986) Structure, organization, and sequence of alpha satellite DNA from human chromosome 17: evidence for evolution by unequal crossing-over and an ancestor pentamer repeat shared with the human X chromosome. Mol Cell Biol 6:3156-3165

Willard HF (1985) Chromosome-specific organization of human alpha satellite DNA. Am J Hum Genet 37:524-532

Willard HF (1990) Centromeres of mammalian chromosomes. Trends Genet 6:410-416

Wong LH, Choo KH (2004) Evolutionary dynamics of transposable elements at the centromere. Trends Genet 20:611616

Yamada H, Li YC, Nishikawa M, Oshimura M, Inoue T (2008) Introduction of a CD40L genomic fragment via a human artificial chromosome vector permits cell-type-specific gene expression and induces immunoglobulin secretion. J Hum Genet 53:447-453 